\title{
Cartilage-Bone Interface Features, Scaffold and Cell Options for Regeneration
}

Ece Bayrak, Burak Ozcan and Cevat Erisken*

Department of Biomedical Engineering, TOBB University of Economics and Technology, Ankara, Turkey

*Corresponding author: Cevat Erisken, Department of Biomedical Engineering, TOBB University of Economics and Technology, Ankara, Turkey, Tel: +79261558870; Email: cerisken@etu.edu.tr

Received date: July 19, 2016; Accepted date: August 05, 2016; Published date: August 10, 2016

Copyright: (c) 2016 Bayrak E, et al. This is an open-access article distributed under the terms of the Creative Commons Attribution License, which permits unrestricted use, distribution, and reproduction in any medium, provided the original author and source are credited.

\section{Introduction}

Tissues with different material and biological properties are connected to one another through interfaces, which can be generally categorized as soft-to-soft tissue interfaces (muscle-tendon, etc.), softto-hard tissue interfaces (cartilage-bone, tendon-bone, etc.) and hardto-hard tissue interfaces (dentin-enamel, etc.). Since these interfaces merge biological materials, i.e., tissues, having distinct composition, structure and function, they possess complexities associated with their hierarchical structures, and when injured their healing/regeneration pathways follow more intricate phenomena compared to single tissues making up the interfaces. Findings reveal that injuries related to tissues connected in series occur mostly at the interfaces due to the mismatch between material properties of individual tissues. Therefore, interface tissue engineering has recently attracted significant attention from academia to be able to understand the mechanism of cell-materials interactions relevant to interfaces. This paper reviews the structure, composition and function of cartilage-bone interface in conjunction with the scaffold and cell options for its regeneration.

\section{Cartilage-Bone Interface}

Osteoarthritis $(\mathrm{OA})$ is a degenerative joint disease seen at the cartilage-bone interface in the knee. It is characterized by the lesions in the articular cartilage at early stages and complete loss of function of the knee joint at advanced stages [1]. OA is known as one of the most common joint-related traumas, and it is reported that, between 2010 and 2012, around 52.5 million adults (18 years and over) were diagnosed with OA and that every 1 of 2 adults over 65 years suffered from OA in the US, only [2]. Unfortunately, widely used clinical approaches (lavage, periosteal grafts, subchondral drilling, microfracture, mozaicplasty, etc.) are far from integrating cartilage tissue to bone biologically. Especially, following mozaicplasty, a gold standard for the repair of large size articular cartilage defects, subchondral bone remains exposed to cartilage tissue through the gaps between inserted plugs. This allows for the advancement of capillaries from bone tissue to cartilage, which eventually leads to formation of a fibrovascular tissue that is mechanically inferior to and biologically different from articular cartilage. The native cartilage-bone interface, on the other hand, was designed to prevent progression of capillaries to cartilage zone by a tiny membrane called tide-mark. Therefore, due to insufficiency of current procedures to form a tide-mark-like zone, repair/regeneration of OA remains as a challenge and new approaches are needed to remedy this problem.

\section{Function, Composition and Structure}

One of the critical functions of native cartilage-bone interface is to minimize the stress concentrations, which may occur between the two tissues when load is applied to one, to form a smooth transition region in order not to overload either tissue. This function is a direct consequence of hierarchical organization of the extracellular matrix (ECM) components forming the interface. Another function of the interface is not to allow capillary development from vascularized bone tissue to avascular cartilage tissue [3], which is accomplished by the tide-mark.

Cartilage-bone interface at the knee joint has a thickness of around 100-200 $\mu \mathrm{m}$ [4] and structurally contains three different yet uninterrupted compartments, namely, cartilage, mineralized cartilage, and bone, containing various cell phenotypes such as chondrocytes, hyperthrophic chondrocytes and osteoblasts, respectively [5]. The major ECM components contained in these sub-tissues are collagen type II and glycosaminoglycans; collagen type I, glycosaminoglycans, minerals; and collagen type I and minerals, respectively (Table 1).

\begin{tabular}{|l|l|l|}
\hline Tissue & Cell Type & Components \\
\hline Cartilage & Chondrocyte & $\begin{array}{l}\cdot \text { Collagen type II } \\
\cdot \text { Glycosaminoglycan }\end{array}$ \\
\hline Mineralized cartilage & Hyperthrophic chondrocyte & $\begin{array}{l}\cdot \text { Collagen Type I, X } \\
\cdot \text { Glycosaminoglycan } \\
\cdot \text { Mineral }\end{array}$ \\
\hline Bone & Osteoblast & $\begin{array}{l}\cdot \text { Collagen Type I } \\
\cdot \text { Mineral }\end{array}$ \\
\hline
\end{tabular}

Table 1: Compositional distribution in cartilage-bone interface.

Another school of thought for the hierarchical organization of the cartilage-bone interface is the belief of graded change in the composition of ECM components [6-9]. Although the compartmental organization approach for cartilage-bone interface components has been dominant for years $[5,10]$, recent studies characterizing cartilagebone, as well as tendon-bone, interface at microscopic dimensions found that mineral composition is changing gradually across the interface $[4,11,12]$.

With the recent increased interest in the field of interface tissue characterization, we are now more equipped with the structure and composition of cartilage-bone interface, which could be translated into design and fabrication of scaffolds for such applications.

\section{Scaffolds for Cartilage-Bone Interface}

One of the methods utilized for the treatment of damages associated with the cartilage-bone interface at the knee is cell therapy (Table 2), applied either directly or in conjuction with scaffolds [13]. Even though cell therapy is a well-recognized and a versatile technique used for regenerative purposes, it has its own drawbacks such as difficulties 
associated with cell isolation, proliferation, storage, transfer, cost (for allogenic sources) and immune system reactions [14,15]. In addition, this technique has limitations due to potential infection, pathogen transfer and tumor growth. Therefore, cellular (with prementioned risks) or acellular scaffolds remain as an attractive alternative for direct cell therapy.

\begin{tabular}{|l|l|l|l|}
\hline Therapy & & Cell & Scaffold \\
\hline \multirow{2}{*}{ Cell-based } & Direct cell transplantation & $\sqrt{ }$ & \\
\cline { 2 - 4 } & Cellular scaffolds & $\sqrt{ }$ & $\sqrt{ }$ \\
\hline Cell-free & Acellular scaffolds & & $\sqrt{ }$ \\
\hline
\end{tabular}

Table 2: Options for regeneration.

As the name implies, cellular scaffolds are structured and shaped biomaterials incorporated with cells. Acellular scaffolds, on the other hand, contain no cells and may be incorporated with chemotactic agents to recruit endogenous cells into the scaffold to initiate regeneration. Cell recruitment represents a more recent development in the regenerative engineering, and is seen as a promising approach. This method was successfully used with $3 \mathrm{D}$ printed polycaprolactone (PCL) scaffolds in a sheep model for mensiscus regeneration [16]. However, cell recruitment has not been utilized in the regeneration attempts for cartilage-bone interface at a scale of 100-200 $\mu \mathrm{m}$ thickness.

Scaffolds utilized for cartilage-bone applications were traditionally designed either as unitary homogeneous [17] or layered configurations $[10,18]$. However, recent investigations at micrscopic levels showed that the osteochondral interface exhibits a gradual change in the composition of the matrix components [12], leading to a paradigm shift in the understanding of scaffold design. Therefore, more recent investigations focused on the design and fabrication of graded scaffolds for osteochondral interface applications $[6,7,19]$. In one of these studies, tricalciumphospate (TCP) mineral was embedded in PCL nanofibers to fabricate scaffolds with gradually changing TCP concentrations [6]. The same group of researchers produced functionally graded PCL scaffolds incorporated with insulin and betaglyserophospate (beta-GP) biomolecules with varying concentrations in opposite direction [7]. Human adipose derived stem cells (hADSCs) were seeded on the graded scaffolds to form osteochondral-like structures. In a similar study, poly (D,L-lactide-co-glycolic acid), PLGA, microspheres were enriched with growth factors, stimulating cartilage and bone formation, in a gradually changing fashion, and their capacity were investigated for the treatment of osteochondral defects in a rabbit femoral condile model [9]. Putting together, these investigations demonstrate that scaffolding for osteochondral tissue engineering is still under development, and that progress in technology will certainly open up new avenues for the design and fabrication of more realistic scaffolds [20].

\section{Cell Options}

Commonly used cell options for the osteochondral interface tissue engineering include but are not limited to chondrocytes, osteoblasts and stem/progenitor cells. Chondrocytes and osteoblasts could be harvested through surgical procedures, proliferated, and used as cell sources to be seeded on scaffolds to form cartilage and bone regions, respectively. Nevertheless, limited availability of these cells due to donor shortages, and morphological changes associated with some cell types, especially for chondrocytes, when cultured under in vitro conditions, stem/progenitor cells remain as a more favourable cell sources.

Chondrocytes harvested from sheep [21] and bovine [22] are commonly used as cell sources for osteochondral regeneration. In addition, co-culture of chondrocytes and osteoblasts obtained from similar sources is also an attractive strategy to form osteochondral-like structures. In this regard, Cao et al. seeded chondrocytes on one side of the 3D printed PCL scaffold and osteoblast on the other side, and observed a mixture of the two distinct cell phenotypes in the middle zone [23].

In the category of stem/progenitor cells, bone marrow derived stem cells, adipose derived stem cells, synovial stem cells and embryonic stem cells were demonstrated to be appropriate cell choices for osteochondral regeneration [24,25]. Specific differentiation of these cells into proper lineages is achieved by incorporating relevant biomolecules into scaffolds in a specially controlled manner. For example, transforming growth factor betal (TGF-beta1) and transforming growth factor beta3 (TGF-beta3) are known to trigger these cells to differentiate into chondrogenic lineage, while bone morphogenic protein 2 (BMP2) can lead to osteogenic differentiaon [26-29]. Therefore, incorporating TGF-betal or TGF-beta3 into one side and BMP2 into the other, also coupled with the stem cells may form appropriate conditions to generate structures resembling the osteochondral interface.

\section{Regeneration Attempts}

Biomaterial/scaffold and biomolecule selection, as well as employment of appropriate cells could play significant roles in osteochondral regeneration efforts. Biomaterials are required to be biologically compatible. They should not create any adverse effects in terms of cell attachment, proliferation, morphology, membrane characteristics and cellular activity such as ECM production and expression of relevant markers. Biomolecules should contribute to the cellular activities in the direction observed in their native environment. Similarly, selected cells are expected to have properties or should have capacities to perform activities of cells present in the target tissues. Tissue regeneration may be possible at best only if these three parameters are chosen appropriately, and combined to create a synergistic effect to be able to generate structures, compositions and functions observed in native osteochondral interface.

Biomaterial/scaffold design targeting osteochondral interface regeneration could be classified as homogeneous (first generation), compartmentalized (second generation), and graded (third generation) scaffolds. Although, the first two generation scaffolds are still widely investigated due to their ease of design/manufacture and simplicity in terms of composition and structure, the third generation graded scaffolds are now more prevalent due to their biomimicry. These scaffolds could be designed to contain multiple biomolecules positioned into the scaffold in a controlled fashion, and to release these biofactors in a time-dependent manner to also serve as controlled delivery devices. Such scaffolds were successfully employed for interface regenerative engineering studies both in vitro and in vivo $[6,7,28]$. These investigations revealed that when the right cells are used in conjunction with an appropriate scaffold and/or scaffold biofactors combination choice, native osteochondral interface could be approximated both biologically and physically. 


\section{References}

1. Nyvang J, Hedström M, Gleissman SA (2016) It's not just a knee, but a whole life: A qualitative descriptive study on patients' experiences of living with knee osteoarthritis and their expectations for knee arthroplasty. Int J Qual Stud Health Well-being 31: 30193.

2. Barbour KE, Helmick CG, Theis KA, Murphy LB, Hootman JM, et al. (2013) Prevalence of doctor-diagnosed arthritis and arthritis-attributable activity limitation — United States. MMWR 62: 869-873.

3. Hunziker EB, Driesang IM, Saager C (2001) Structural barrier principle for growth factor-based articular cartilage repair. Clin Orthop Relat Res 391: S182-S189.

4. Khanarian NT, Boushell MK, Spalazzi JP, Pleshko N, Boskey AL, et al. (2014) FTIR-I compositional mapping of the cartilage-to-bone interface as a function of tissue region and age. Journal of Bone and Mineral Research 29: 2643-2652

5. Atesok K, Doral MN, Karlsson J, Egol KA, Jazrawi LM, et al. (2014) Multilayer scaffolds in orthopaedic tissue engineering. Knee Surg Sports Traumatol Arthrosc 3: 1-9.

6. Erisken C, Kalyon DM, Wang H (2008) Functionally graded electrospun polycaprolactone and beta-tricalcium phosphate nanocomposites for tissue engineering applications. Biomaterials 29: 4065-4073.

7. Erisken C, Kalyon DM, Wang H, Örnek-Ballanco C, Xu J (2011) Osteochondral tissue formation through adipose-derived stromal cell differentiation on biomimetic polycaprolactone nanofibrous scaffolds with graded insulin and $\beta$-glycerophosphate concentrations. Tissue Engineering Part A 17: 1239-1252.

8. Dormer NH, Singh M, Zhao L, Mohan N, Berkland CJ, et al. (2012) Osteochondral interface regeneration of the rabbit knee with macroscopic gradients of bioactive signals. J Biomed Mater Res A 100: 162-170.

9. Bayrak E, Ozcan B, Erisken C (2016) Processing of polycaprolactone and hydroxyapatite to fabricate graded electrospun composites for tendonbone interface regeneration. Journal of Polymer Engineering doi: 10.1515/polyeng-2016-0017.

10. Khanarian NT, Jiang J, Wan LQ, Mow VC, Lu HH (2012) A hydrogelmineral composite scaffold for osteochondral interface tissue engineering. Tissue Engineering Part A 18:533-545.

11. Bradley DA, Muthuvelu P, Ellis RE, Green EM, Attenburrow D, et al (2007) Characterisation of mineralisation of bone and cartilage: X-ray diffraction and $\mathrm{Ca}$ and $\mathrm{Sr} \mathrm{Ka} \mathrm{X}$-ray fluorescence microscopy. Nucl Instrum Meth B 263: 1-6.

12. Genin GM, Kent A, Birman V, Wopenka B, Pasteris JD, et al.(2009) Functional grading of mineral and collagen in the attachment of tendon to bone. Biophys J 97: 976-985.

13. Hutmacher DR (2000) Scaffolds in tissue engineering of bone and cartilage. Biomaterials 21: 2529-2543.

14. Ikada Y (2006) Challenges in tissue engineering. Journal of The Royal Society Interface 3: 589-601.

15. Chan BP, Leong KW (2008) Scaffolding in tissue engineering: general approaches and tissue-specific considerations. European Spine Journal 17: 467-479.
16. Lee CH, Rodeo SA, Fortier LA, Lu C, Erisken C, et al. (2014) Proteinreleasing polymeric scaffolds induce fibrochondrocytic differentiation of endogenous cells for knee meniscus regeneration in sheep. Science Translational Medicine 6: 266ra171.

17. Tuli R, Nandi S, Li WJ, Tuli S, Huang X, et al. (2004) Human mesenchymal progenitor cell-based tissue engineering of a single-unit osteochondral construct. Tissue Eng 10: 1169-1179.

18. Kon E, Delcogliano M, Filardo G, Altadonna G, Marcacci M (2009) Novel nano-composite multi-layered biomaterial for the treatment of multifocal degenerative cartilage lesions. Knee Surg Sports Traumatol Arthrosc 17:1312-1315.

19. Han F, Zhou F, Yang X, Zhao J, Zhao Y, et al. (2015) A pilot study of conically graded chitosan-gelatin hydrogel/PLGA scaffold with dualdelivery of TGF-B1 and BMP-2 for regeneration of cartilage-bone interface. Society for Biomaterials 103: 1344-1353.

20. Sherwood JK, Riley SL, Palazzolo R, Brown SC, Monkhouse DC et al. (2002) A three-dimentional osteochondral composite scaffold for articular cartilage repair. Biomaterials 23: 4739-4751.

21. Allan KS, Pilliar RM, Wang J, Grynpas MD, Kandel RA, et al. (2007) Formation of biphasic constructs containing cartilage with a calcified zone interface. Tissue Eng 13: 167-177.

22. Cao T, Ho KH, Teoh SH (2003) Scaffold design and in vitro study of osteochondral co-culture in a three-dimensional porous polycaprolactone scaffold fabricated by fused deposition modeling. Tissue Eng 9: 103-112.

23. Charbord P, Livne E, Gross G, Häupl T, Neves NM, et al. (2011) Human bone marrow mesenchymal stem cells: A systematic reappraisal via the genostem experience. Stem Cell Reviews and Reports 7: 32-42.

24. Guilak F, Estes BT, Diekman BO, Moutos FT, Gimble JM (2010) 2010 Nicolas Andry award: Multipotent adult stem cells from adipose tissue for muscoskeletal tissue engineering. Clinical Orthopaedics and Related Research 468: 2530-2540.

25. Mueller MB, Fischer M, Zellner J, Berner A, Dienstknecht T, et al. (2010) Hyperthrophy in mesencymal stem cell chondrogenesis: Effect of TGF-B isoforms and chondrogenic conditioning. Cells Tissues Organs 192: 158-166.

26. Goessler UR, Bugert P, Bieback K, Deml M, Sadick H, et al. (2005) In vitro analysis of the expression of TGF-B-superfamily members during chondrogenic differentiation of mesenchymal stem cells and chondrocytes during dedifferentiation in cell culture. Cellular \& Molecular Biology Letters 10: 345-362.

27. Park JS, Yang HN, Jeon SY, Woo DG, Na K, et al. (2010) Osteogenic differentiation of human mesenchymal stem cells using RGD-modified BMP-2 coated microspheres. Biomaterials 31: 6239-6248.

28. Luu HH, Song WX, Luo X, Manning D, Luo J, Deng ZL, et al. (2007) Distinct roles of bone morphogenic proteins in osteogenic differentiation of mesencymal stem cells. Journal of Orthopaedic Research 25: 665-677.

29. Holmes B, Zhu W, Li J, Lee JD, Zhang LG (2015) Development of novel three-dimensional printed scaffolds for osteochondral regeneration. Tissue Eng Part A 21: 403-415. 